\title{
Curriculum Evaluation of Internet of Vehicles Converted from Electronic Information Engineering
}

\author{
Zou Qingyu, a and Dejun Liu, ${ }^{1, b^{*}}$ \\ ${ }^{1,2}$ College of Electrical and Information Engineering of Beihua University, Jilin, China \\ azouqingyu2002@126.com, bdejunliu@126.com \\ * The corresponding author
}

Keywords: Internet of Vehicles; Complex Network; Evaluation

\begin{abstract}
Internet of vehicles is a new professional, involving real-time access to vehicle data, car road and shore information exchange, traffic data analysis and processing of key technologies and public transport information services, big data and cloud computing. In this paper, we analyze the curriculum structure of internet of vehicles which transition from the electronic information engineering based on complex network theory. We construct the complex network models of electronic information engineering and internet of vehicles. And then we analyze the topology structure of network after replace the main course. The results show that the proposed network model can accurately assess the impact of curriculum changes on the curriculum system.
\end{abstract}

\section{Introduction}

The transformation and development of local undergraduate colleges is the basic requirement of the society to cultivate the talents of higher education. Internet of vehicles as a new professional, including car network application system design, vehicle network communications, modern sensors, information processing, automotive embedded and other technical content. The aim is to cultivate high-quality applied compound talents who can work in scientific research, system integration, equipment manufacturing, key technology research and development and extension, network operation and management in various industries related to internet of vehicles industry. Electronic Information Engineering is a professional in electronics and information engineering. The professional students mainly learn the signal acquisition and processing, power plant equipment information systems and other aspects of professional knowledge. By the electronic information engineering professional transformation and upgrading into a car network professional is a direct and effective professional transformation model. In this paper, we constructs the network model of electronic information engineering and internet of vehicles curriculum system based on the theory of complex network, which nodes in the network represent the courses and links are the relationship between the courses. And then accurate evaluation of internet of vehicles professional courses on the curriculum system by the analysis of the network topology, which are "Introduction to internet of vehicles ", "Linux operating system", "Linux C programming", "Java SE programming", "Oracle Database Development" and "Android programming" and "Development Technology and Practice of Vehicle Mobile Application".

\section{Construction of Curriculum Relationship Network}

The curriculum is an organic whole that has a specific direction that consists of a multitude of courses that interact with each other. The complex network model consists of nodes and edges. The nodes in the network represent the courses in the course system, and the links between the nodes represent the interrelationships between the courses. Using the complex network model to describe the curriculum system could fully express the relationship between the curriculum structure [1-4].

Construction of Courses Relationship Network Model of Electronic Information Engineering. The main research direction of electronic information engineering is the acquisition and processing of information, including the transmission, processing and storage of information. The application of 
electronic information engineering in modern society is very extensive, such as mobile Internet, Internet of things, internet of vehicles, multimedia information processing and application, intelligent transportation and navigation, underwater submarines, lunar robots, ultra-high-definition television, , Radar, military and military communications. The professional has a total of more than 70 courses, including circuit theory, information theory and coding, signal and system, digital signal processing, electromagnetic theory, automatic control principle. We chose 66 important courses as shown in Table 1 to build a curriculum relationship network.

We build a curriculum relationship network based on the interdisciplinary relationship of the curriculum. The network is a directed and weighted network. The nodes in the network are the courses in Table 1. The edge of the network is the relationship between the courses. The weight of a course is the size of a course that affects another course. For example, the Advanced Mathematics course is the basic course for signal and system courses. More than $50 \%$ of the signal and system course knowledge is related to higher mathematical knowledge. Thus, there is a slight difference between the higher mathematics and the two nodes of the signal and the system, with an edge weight of 0.5. Electronic information engineering courses network as shown in Fig. 1. The network contains 66 nodes, 620 links, the average degree is 1.3338 , the average out-closeness is 5.7023, the average in-closeness is 4.6657 , global clustering coefficient is 0.793 [5-9].

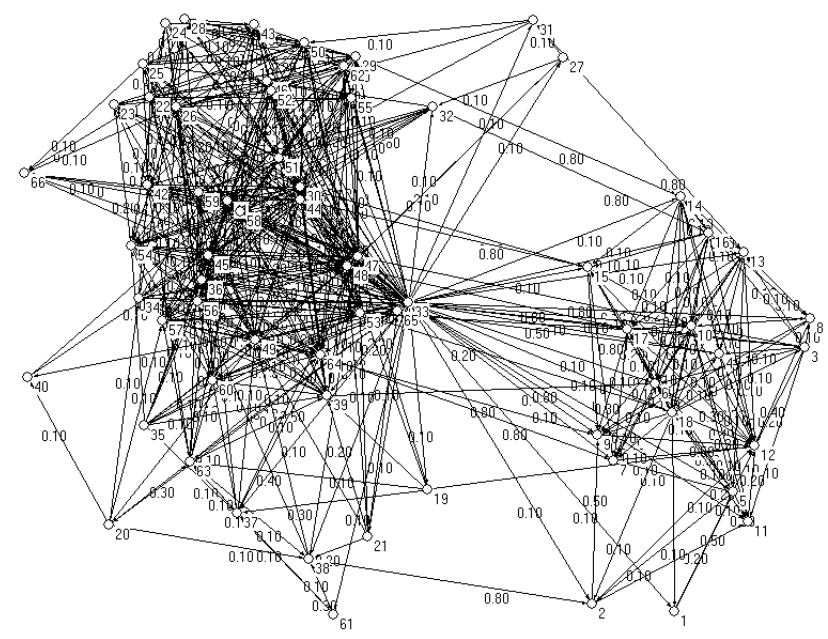

Figure 1. Courses Relationship Network Model of Electronic information engineering

Internet of Vehicles Professional Curriculum Network. Internet of vehicles increased "Introduction to internet of vehicles ", "Linux operating system", "Linux C programming", "Java SE programming", "Oracle Database Development" and "Android programming" and "Development Technology and Practice of Vehicle Mobile Application" Curriculum based on electronic information engineering. The curriculum network as shown in Fig. 2. The network contains 73 nodes, 692 links, the average degree is 2.7233 , the average out-closeness is 5.5972 , the average in-closeness is 4.9983 , the global clustering coefficient is 0.7688 . 
Table 1 Courses of electronic information engineering

\begin{tabular}{|c|c|c|c|c|c|}
\hline No. & Course name & No. & Course name & No. & Course name \\
\hline 1 & $\begin{array}{l}\text { Basic manufacturing } \\
\text { technology practice }\end{array}$ & 23 & Linear Algebra & 45 & $\begin{array}{l}\text { Industrial field bus control } \\
\text { technology }\end{array}$ \\
\hline 2 & $\mathrm{VC}++$ practice & 24 & Probability and Statistics & 46 & $\begin{array}{l}\text { Knowledge extension of } \\
\text { signal and system theory }\end{array}$ \\
\hline 3 & $\begin{array}{l}\text { Electronic technology } \\
\text { practice }\end{array}$ & 25 & $\begin{array}{l}\text { Complex Analysis and } \\
\text { Integral Transformation }\end{array}$ & 47 & Electronic System Design \\
\hline 4 & EDA practice & 26 & Physics of college & 48 & $\begin{array}{l}\text { DSP Technology and } \\
\text { Application }\end{array}$ \\
\hline 5 & Production practice & 27 & Physics of college experiment & 49 & Image Processing Technique \\
\hline 6 & MCU interface practice & 28 & Analog Electronic Technique & 50 & Electromagnetic Field Theory \\
\hline 7 & $\begin{array}{l}\text { ARM information system } \\
\text { practice }\end{array}$ & 29 & Circuit Theory & 51 & Electronic Measurement \\
\hline 8 & DSP practice & 30 & Digital Electronic Technique & 52 & Television technique \\
\hline 9 & Image processing practice & 31 & $\begin{array}{c}\text { Analog Electronic Technique } \\
\text { experiment }\end{array}$ & 53 & $\begin{array}{c}\text { DSP Engineering Case } \\
\text { Analysis }\end{array}$ \\
\hline 10 & $\begin{array}{l}\text { Electronic system } \\
\text { engineering practice }\end{array}$ & 32 & $\begin{array}{c}\text { Digital Electronic Technique } \\
\text { experiment }\end{array}$ & 54 & $\begin{array}{l}\text { Technology of Information } \\
\text { and Coding }\end{array}$ \\
\hline 11 & Graduation practice & 33 & The Professional Introduction & 55 & $\begin{array}{c}\text { Digital Speech Processing } \\
\text { Technique } \\
\end{array}$ \\
\hline 12 & Graduation design & 34 & $\begin{array}{l}\text { Micro-Computer Principle } \\
\text { And Application }\end{array}$ & 56 & $\begin{array}{l}\text { Pattern Identificatio nand } \\
\text { Application }\end{array}$ \\
\hline 13 & Circuit CAD practice & 35 & The Special English & 57 & Multimedia technique \\
\hline 14 & Electronic circuit practice & 36 & Sensors Technology & 58 & $\begin{array}{c}\text { Digital communication } \\
\text { system }\end{array}$ \\
\hline 15 & Digital electronic practice & 37 & Java Program Designing & 59 & $\begin{array}{c}\text { Optical Fiber Communication } \\
\text { Techniques }\end{array}$ \\
\hline 16 & Electronic CAD practice & 38 & VC++ Programing & 60 & $\begin{array}{l}\text { The New technology of } \\
\text { electronic information }\end{array}$ \\
\hline 17 & $\begin{array}{l}\text { DSP Comprehensive } \\
\text { Practice }\end{array}$ & 39 & $\begin{array}{l}\text { Single-chip Micro-computer } \\
\text { And Interface Technology }\end{array}$ & 61 & $\begin{array}{c}\text { Application Technology of } \\
\text { Database }\end{array}$ \\
\hline 18 & College Chinese & 40 & $\begin{array}{l}\text { Mechanical Drawing and } \\
\text { CAD }\end{array}$ & 62 & Microwave Technique \\
\hline 19 & College Foreign Language & 41 & Signal and System & 63 & Computer Networks \\
\hline 20 & $\begin{array}{l}\text { University Computer } \\
\text { Foundation }\end{array}$ & 42 & $\begin{array}{l}\text { The Principle of } \\
\text { Communication }\end{array}$ & 64 & $\begin{array}{l}\text { Embedded Systems and } \\
\text { Application }\end{array}$ \\
\hline 21 & $\begin{array}{l}\text { Computer programming } \\
\text { (C language) }\end{array}$ & 43 & $\begin{array}{c}\text { High frequency electronics } \\
\text { Technology }\end{array}$ & 65 & $\begin{array}{l}\text { EDA Technology and } \\
\text { Application }\end{array}$ \\
\hline 22 & Advanced Mathematics & 44 & Digital Signal Processing & 66 & Automatic Control Theory \\
\hline
\end{tabular}




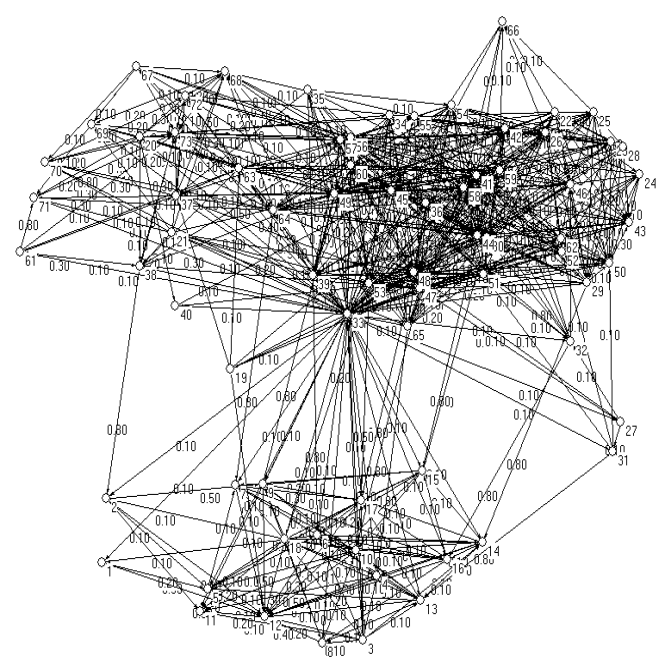

Figure 2. Courses Relationship Network Model of Internet of Vehicles

\section{Curriculum Evaluation of Degree Distribution Based on Degree Distribution}

Degree is also called connectivity. It is one of the simplest and most important attributes of a network node $[10,11]$. The degree of the node is the number of all edges connected to it. In the directional network, the degree of the node is divided into in-degree and out-degree. In the network with adjacency matrix $A(n \times n)$, if there is an edge from node $i$ to node $j$, then $A_{i j}=1$, then the out-degree $k^{\text {out }}$ and in-degree $k^{\text {in }}$ of nodes are respectively.

$k_{i}^{\text {out }}=\sum_{j=1}^{n} A_{i j}, \quad k_{j}^{\text {in }}=\sum_{i=1}^{n} A_{i j}$

The distribution of nodes in the network is one of the most important attributes. It can be described by the distribution function $P(k)$ and the cumulative distribution function $P_{c}(k) . P(k)$ represents the proportion of nodes with degrees $k$ in all nodes, and $P_{c}(k)$ represents the proportion of nodes with degrees greater than or equal to $k$ in all nodes. The degree and degree cumulative distribution of electronic information engineering as shown in Fig. 3. The degree and degree cumulative distribution of intelligent hardware and product design as shown in Fig. 4. We replace Automatic Control Theory, Embedded Systems and Application, VC++ Programing, Java Program Designing, Micro-Computer Principle and Application, Multimedia technique, EDA Technology and Application rapid Introduction to internet of vehicles, Linux operating system, Linux C programming, Java SE programming, Oracle Database Development and Android programming, Development Technology and Practice of Vehicle Mobile Application, respectively. The degree and degree cumulative distribution of intelligent hardware and product design as shown in Fig. 5.
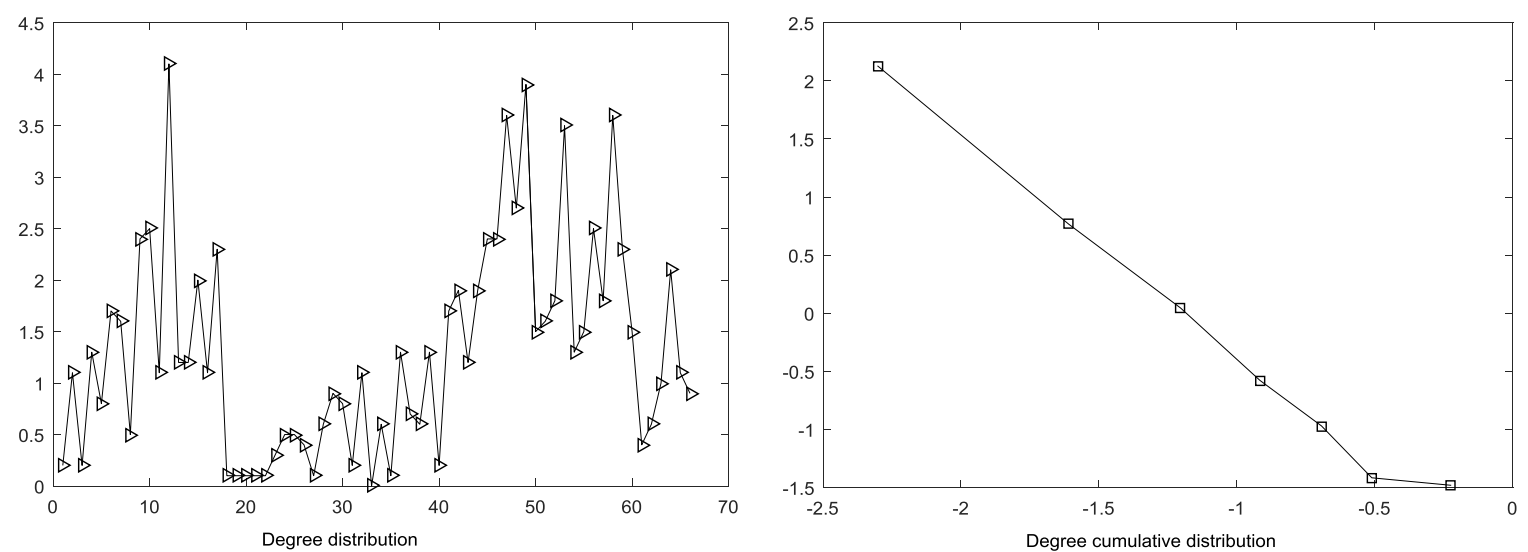

Figure 3. Degree and cumulative degree distribution of electronic information engineering 

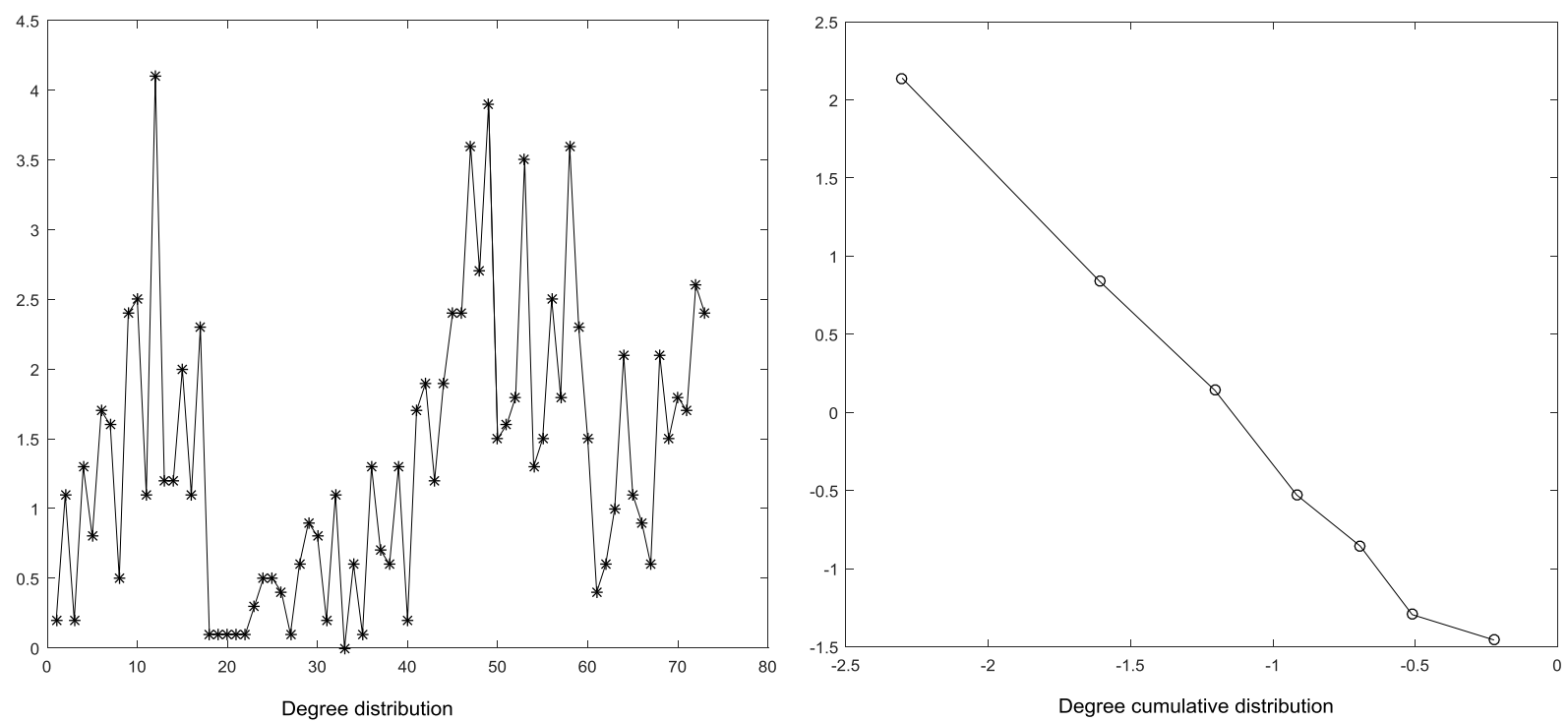

Figure 4. Degree and cumulative degree distribution of internet of vehicles
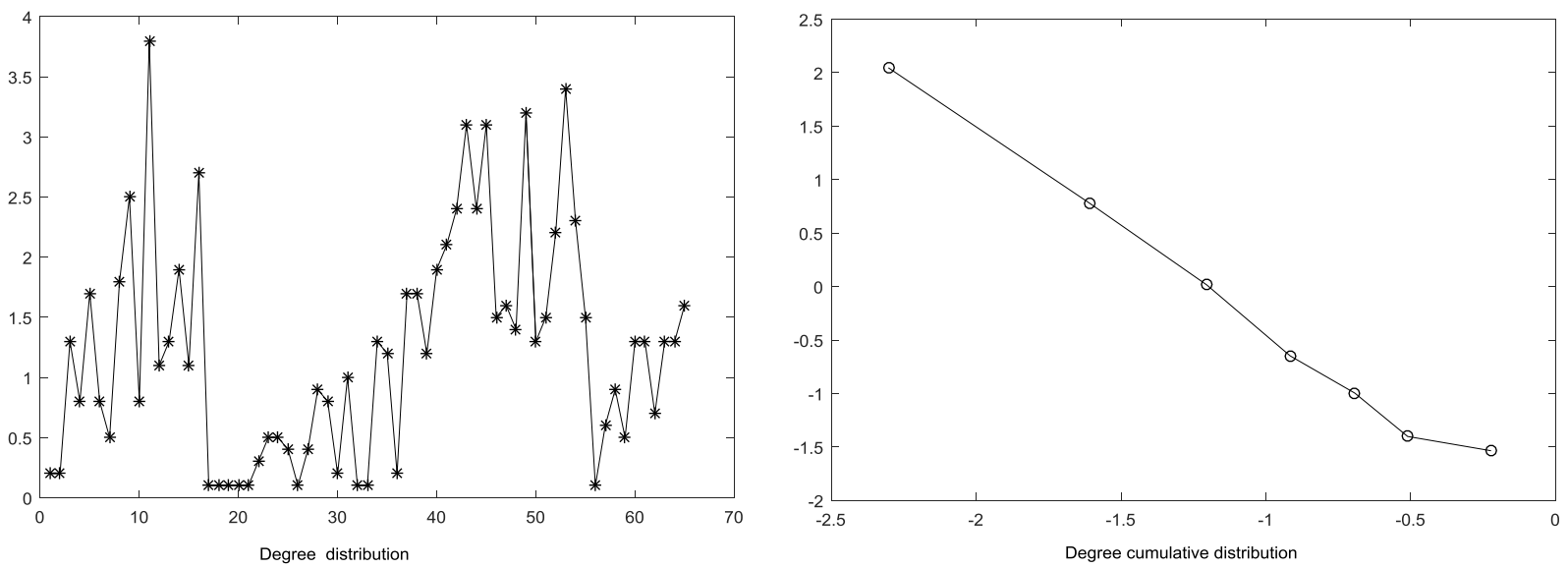

Figure 5. Degree and cumulative degree distribution of internet of vehicles after the replacement of courses

\section{Summary}

Internet of vehicles is the inevitable product of social development. In this paper we analyzes the curriculum system of electronic information engineering and internet of vehicles based on the theory of complex network. Firstly, the network models of electronic information engineering and internet of vehicles are constructed. And then we replace the main course, and once again on the network topology analysis. The results show that the model can accurately evaluate the influence of curriculum changes on the professional curriculum system.

\section{Acknowledgement}

This work is supported partially by the Key Education Research Project of Beihua university (Grant NO. XJZD2016039), partially by the Jilin Province Science and Technology Development Project(Grant NO. 20170520057JH), partially by the Beihua University Dr. Scientific Research Fund (Grant NO. 199500103), partially by the university-enterprise cooperation comprehensive reform project of intelligent information processing and networking professionals (Grant NO. SJXQ001). 


\section{References}

[1] Shimada, Y., Hirata, Y., Ikeguchi, T., et al. Graph distance for complex networks. Scientific Reports, 2016, 6

[2] Schich, M. and Meirelles, I. Arts, Humanities and Complex Networks: Introduction. Leonardo, 2016, 49(5): 445-445.

[3] Rodrigues, F. A., Peron, T., Ji, P., et al. The Kuramoto model in complex networks. Physics Reports-Review Section of Physics Letters, 2016, 610: 1-98.

[4] Zanin, M., Papo, D., Sousa, P. A., et al. Combining complex networks and data mining: Why and how. Physics Reports-Review Section of Physics Letters, 2016, 635: 1-44.

[5] Wang, X. R., Trajanovski, S., Kooij, R. E., et al. Degree distribution and assortativity in line graphs of complex networks. Physica a-Statistical Mechanics and Its Applications, 2016, 445: 343-356.

[6] Zhang, Y., Zhang, Z., Guan, J., et al. An analytic derivation of clustering coefficients for weighted networks. Journal of Statistical Mechanics-Theory and Experiment, 2010,

[7] Du, Y., Gao, C., Chen, X., et al. A new closeness centrality measure via effective distance in complex networks. Chaos, 2015, 25(3)

[8] Xiang, J., Hu, T., Zhang, Y., et al. Local modularity for community detection in complex networks. Physica a-Statistical Mechanics and Its Applications, 2016, 443: 451-459.

[9] Wei, D. J., Chen, X. W. and Deng, Y. Multifractality of weighted complex networks. Chinese Journal of Physics, 2016, 54(3): 416-423.

[10] Egerstedt, M. COMPLEX NETWORKS Degrees of control. Nature, 2011, 473(7346): 158-159.

[11] Ghoshal, G. and Newman, M. E. J. Growing distributed networks with arbitrary degree distributions. European Physical Journal B, 2007, 58(2): 175-184. 